\title{
The Selection of Materials for Marine Gas Turbine Engines
}

\author{
I. Gurrappa1, I. V. S. Yashwanth ${ }^{2}$ and A. K. Gogia ${ }^{1}$ \\ ${ }^{1}$ Defence Metallurgical Research Laboratory, Kanchanbagh PO, Hydereabad \\ ${ }^{2}$ M.V.S.R. Engineering College, Nadargul, Hyderabad
}

India

\section{Introduction}

The desire forever-greater efficiency and increased performance has driven the development in modern gas turbine engines. These engines require high performance materials to exhibit maximum efficiency by increasing their operating temperatures. The blades in modern aero, marine and industrial gas turbines are manufactured exclusively from nickel based superalloys and the compressor section components from titanium based alloys (Fig.1). Achieving enhanced efficiency for marine gas turbines is a major challenge as the surrounding environment is highly aggressive. This aspect depends not only on the design but also on the selection of appropriate materials for their construction. Between the two, selection of materials plays a vital role as the materials have to perform well for the designed period under severe marine environmental conditions. The marine environment makes the superalloys and / or titanium based alloys to undergo a process namely hot corrosion. Hot corrosion can be divided into two types i.e. type I which takes place between

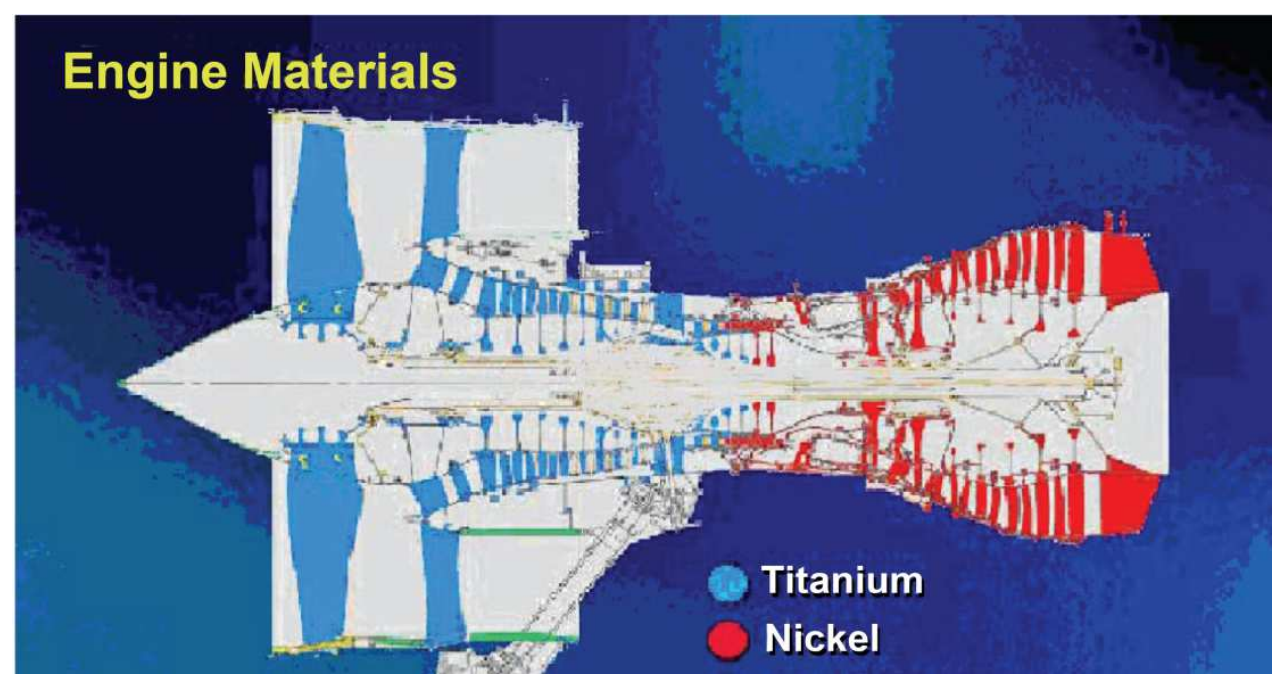

Fig. 1. Significance of superalloys and titanium alloys in gas turbine engines 
800 and $950^{\circ} \mathrm{C}$ and type II that takes place from 600 to $750^{\circ} \mathrm{C}$. At higher temperatures, there is no hot corrosion problem as the salt evaporates. Unlike oxidation, hot corrosion is highly detrimental. In fact, hot corrosion is a limiting factor for the life of components for marine gas turbines. Vanadium that is present in the fuel makes the marine environment further corrosive by forming low melting point chemical compounds. Therefore, selection of appropriate materials is paramount importance. An ideal construction material should be able to survive this harsh corrosive environment. Thus, in order to improve the efficiency of marine gas turbine engines significantly, either the existing materials / coatings which can exhibit very good hot corrosion resistance or the advanced materials with considerably improved properties are necessary. Efforts made in this direction made it possible to develop a new superalloy which exhibits excellent high temperature strength properties [1].
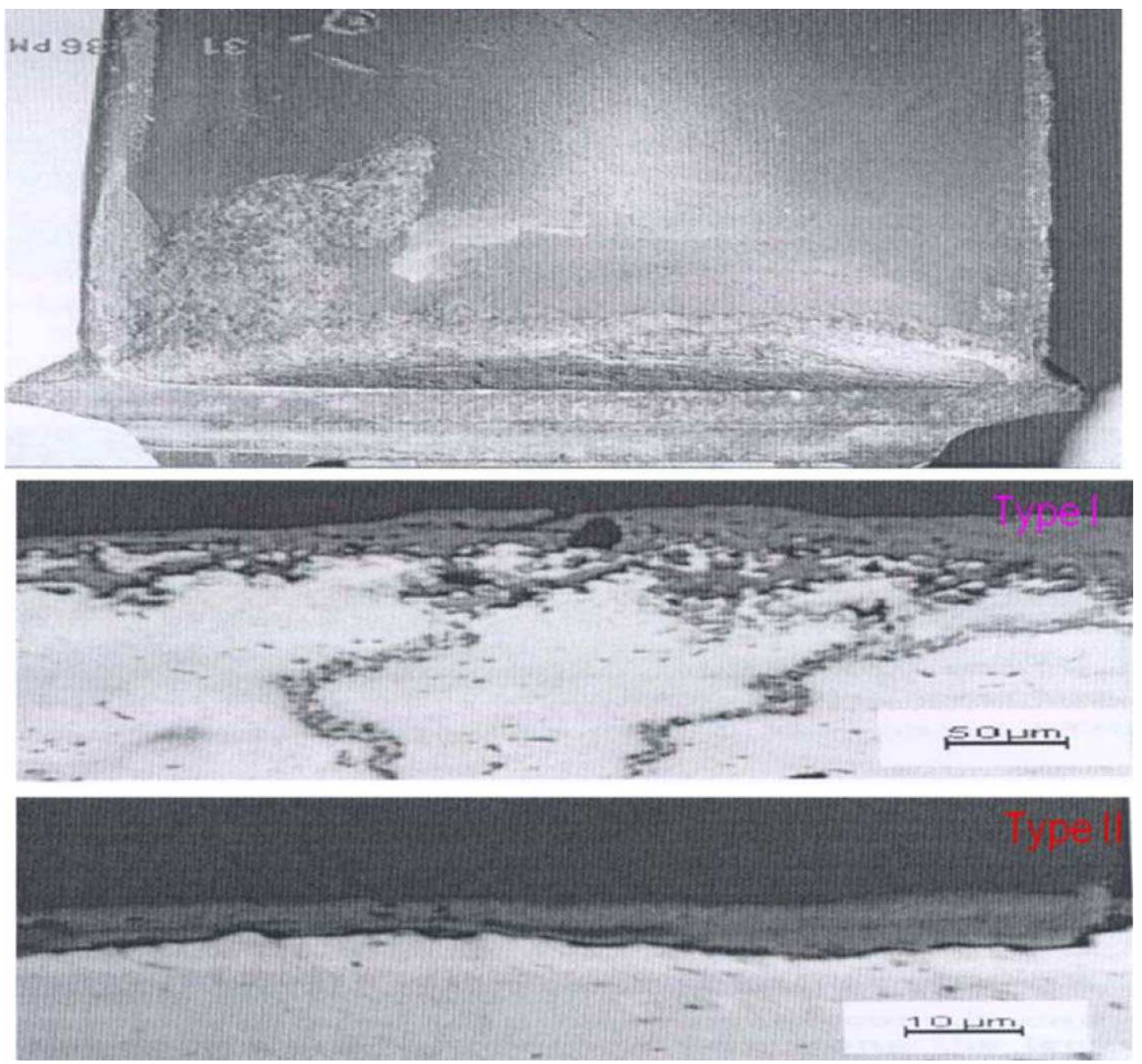

Fig. 2. Failed gas turbine blade due to type I and II hot corrosion

The majority of nickel based superalloy developmental efforts have been directed towards improving the alloy high temperature strength properties with relatively minor concern 
being shown to its hot corrosion resistance. Further, it is not always possible to achieve both high temperature strength and hot corrosion resistance simultaneously because some alloying elements help to improve hot corrosion resistance while some may help to improve high temperature strength. It is rare that an alloying element leads to enhancement both in high temperature strength and the hot corrosion resistance simultaneously. This is further complicated for marine applications by the aggressivity of the environment, which includes sulphur and sodium from the fuel and various halides contained in seawater. These features are known to drastically reduce the superalloy component life and reliability by consuming the material at an unpredictably rapid rate, thereby reducing the load-carrying capacity and potentially leading to catastrophic failure of components (Fig.2) [2-4]. Thus, the hot corrosion resistance of superalloys is as important as its high temperature strength in marine gas turbine engine applications [5-8]. Recent studies have shown that the high temperature strength materials are most susceptible to hot corrosion and the surface engineering plays a key role in effectively combating the hot corrosion problem [9-13].

\section{Superalloys}

The selected superalloys for the investigation are presented in Table 1. It is to be noted that SU 263, SU 718, IN 738 LC and IN 792 superalloys contain no rhenium but sufficient amount of chromium. However, SU 263 contains $6 \%$ molybdenum and $20 \%$ cobalt, iron content is very high in SU 718 with $6 \%$ tungsten, $6.5 \%$ tantalum and reduced molybdenum $3 \%$. Good amount of tantalum and cobalt $8.5 \%$ each and further reduction in molybdenum $1.75 \%$ make IN 738 LC. IN 792 contains very low content of tungsten, molybdenum, more amount of aluminium $7.6 \%$ and tantalum $5 \%$ while CMSX-4 superalloy has $3 \%$ rhenium and reduced chromium. The newly developed alloy contains $6.5 \%$ rhenium and a very small amount of chromium. The modified chemistry with $6.5 \%$ rhenium, $8.5 \%$ tantalum and $5.8 \%$ tungsten makes the new superalloy to exhibit very good high temperature strength properties [1].

\begin{tabular}{|l|c|c|c|c|c|c|c|c|c|c|c|c|c|c|}
\hline Superalloy & $\mathrm{Ni}$ & $\mathrm{Cr}$ & $\mathrm{Co}$ & $\mathrm{W}$ & $\mathrm{Al}$ & $\mathrm{Ta}$ & $\mathrm{Ti}$ & $\mathrm{Mo}$ & $\mathrm{Re}$ & $\mathrm{Hf}$ & $\mathrm{Fe}$ & $\mathrm{Mn}$ & $\mathrm{Si}$ & $\mathrm{Nb}$ \\
\hline SU-263 & Bal & 20 & 20 & - & 0.6 & 1.3 & 2.4 & 6.0 & - & - & 0.7 & 0.6 & 0.4 & - \\
\hline SU-718 & 52.5 & 18.5 & 9.0 & 6.0 & 0.5 & 6.5 & 0.9 & 3.0 & - & - & 19.0 & 0.2 & 0.2 & 5.1 \\
\hline IN 738 LC & Bal & 16 & 8.5 & 2.6 & 3.4 & 8.5 & 3.4 & 1.75 & - & - & - & 0.2 & 0.3 & 0.9 \\
\hline IN 792 & Bal & 13.5 & 9.0 & 1.2 & 7.6 & 1.3 & 5.0 & 1.2 & - & 0.2 & 0.5 & - & - & - \\
\hline CMSX-4 & Bal & 6.5 & 9.0 & 6.0 & 5.6 & 6.5 & 1.0 & 0.6 & 3.0 & 0.1 & - & - & - & - \\
\hline CM 247 LC & Bal & 8.1 & 9.2 & 8.5 & 5.6 & 3.2 & 0.7 & 0.5 & - & 1.4 & - & - & - & - \\
\hline New alloy & Bal & 2.9 & 7.9 & 5.8 & 5.6 & 8.5 & - & - & 6.5 & 0.1 & - & - & - & - \\
\hline
\end{tabular}

Table 1. The chemical composition of selected superalloys ( $w \mathrm{t} \%$ ) 
As hot corroded superalloys like SU 263, SU 718, IN 738 LC in marine and vanadium containing environments under both type II and type I conditions are presented in figures 35, while figures 6 and 7 show the hot corroded IN 792, CMSX-4, new superalloy under type II and type I conditions. As can be seen, all the selected superalloys were severely corroded under both the conditions. However, the corrosion is more severe under type I when compared to type II conditions. It indicates that all the superalloys are highly susceptible to hot corrosion. Among them, the new superalloy is more vulnerable to hot corrosion. The new alloy degrades at a very faster rate making it difficult to recognize over a period of time as evidenced from the experiments (Fig.8). It is clearly indicating that the modified chemistry of the new superalloy could not improve its hot corrosion resistance. However, it exhibits very good high temperature strength characteristics as mentioned earlier.

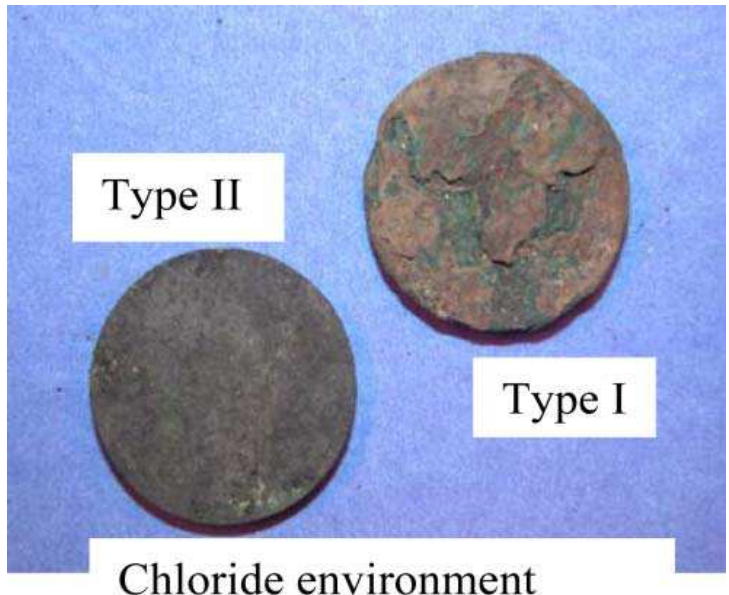

Chloride environment

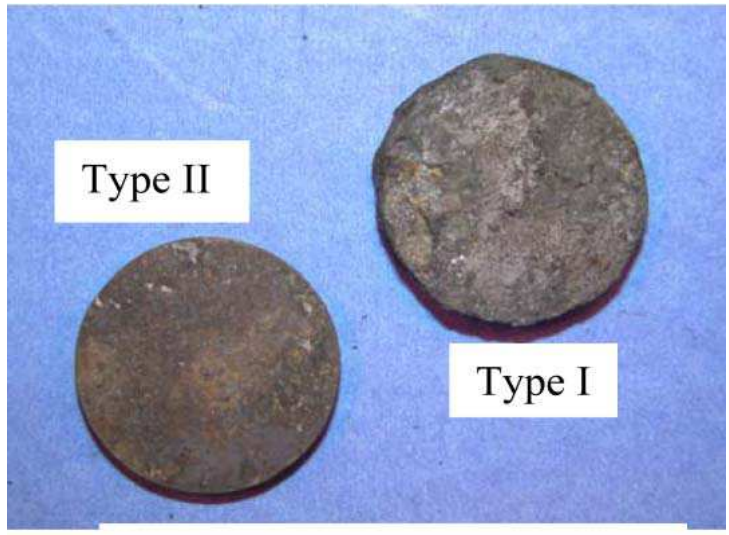

Vanadium environment

Fig. 3. As hot corroded superalloy SU-263 in marine and vanadium containing environments under type I and type II conditions 


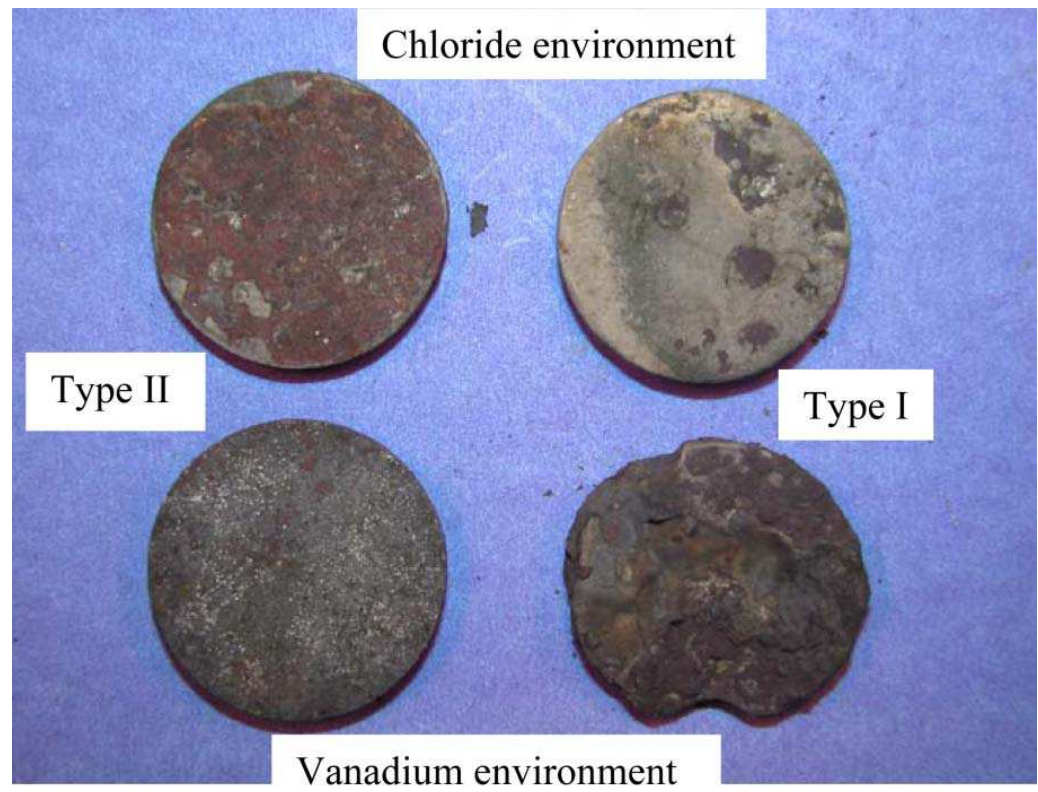

Fig. 4. As hot corroded superalloy SU-718 in marine and vanadium containing environments under type I and type II conditions

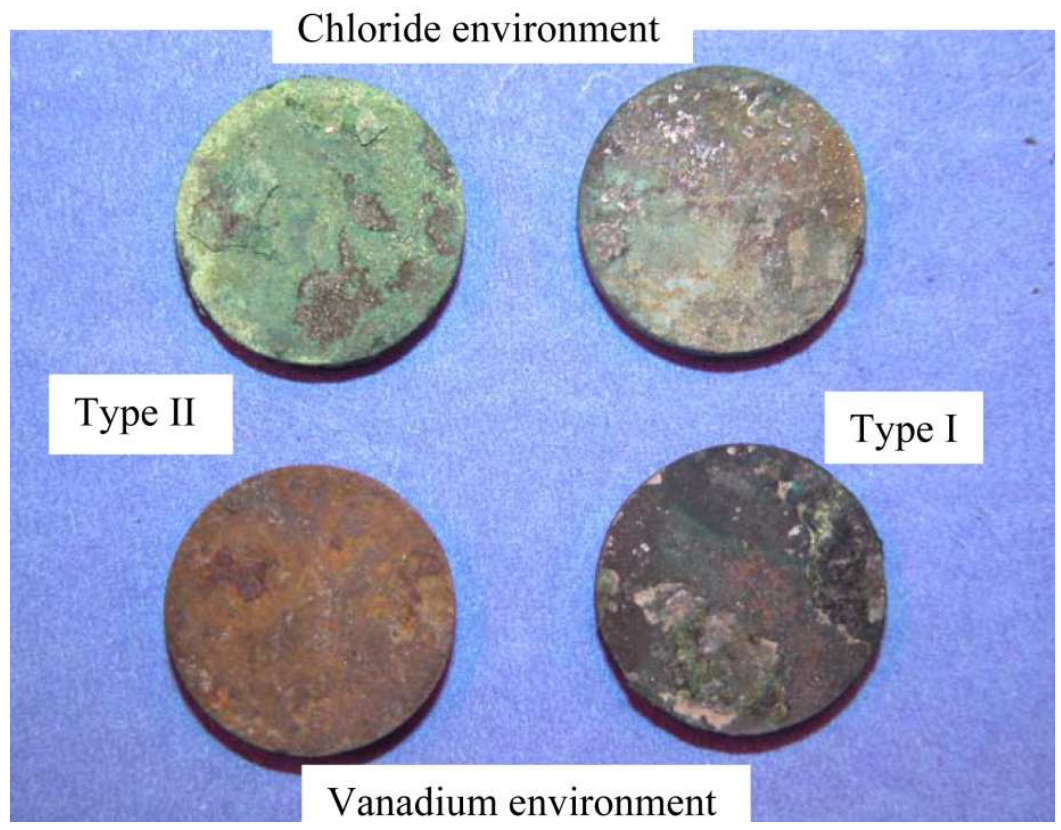

Fig. 5. As hot corroded superalloy IN 738 LC in marine and vanadium containing environments under type I and type II conditions 


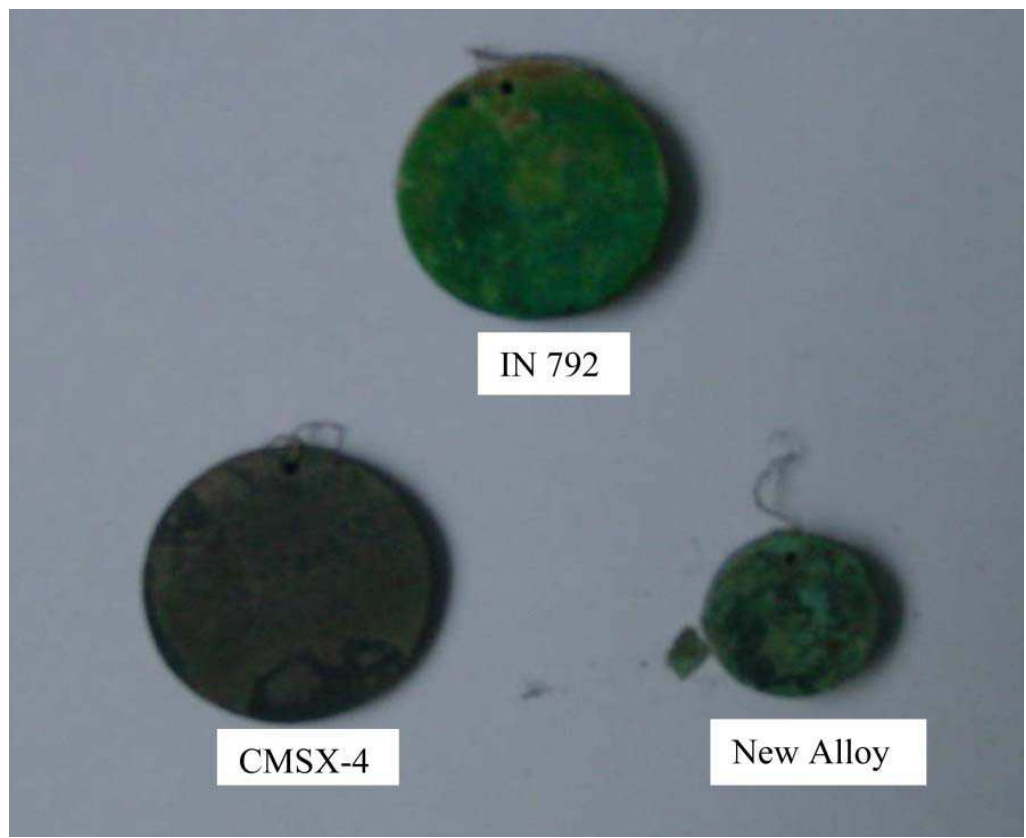

Fig. 6. As hot corroded superalloys in marine environment under type II conditions

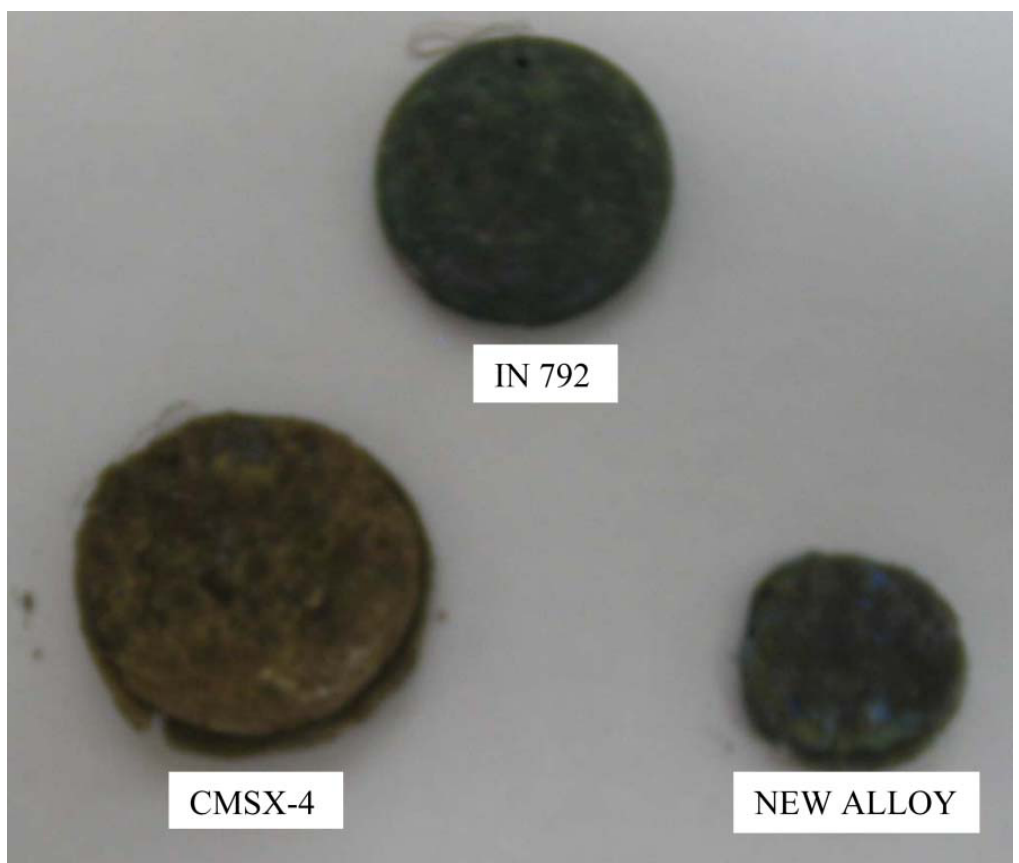

Fig. 7. As hot corroded superalloys under type I conditions in marine environment 


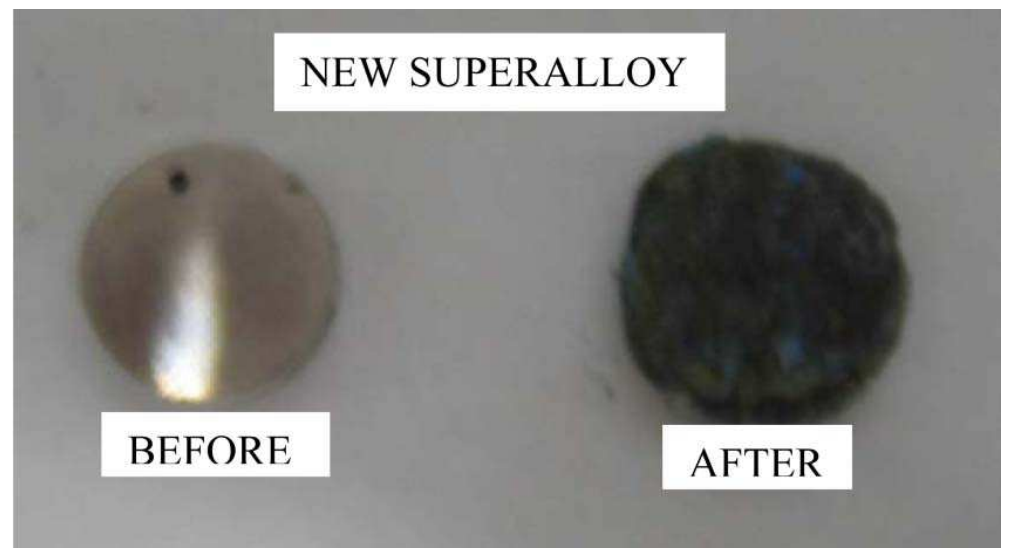

Fig. 8. Before and after hot corrosion in marine environment under type I conditions
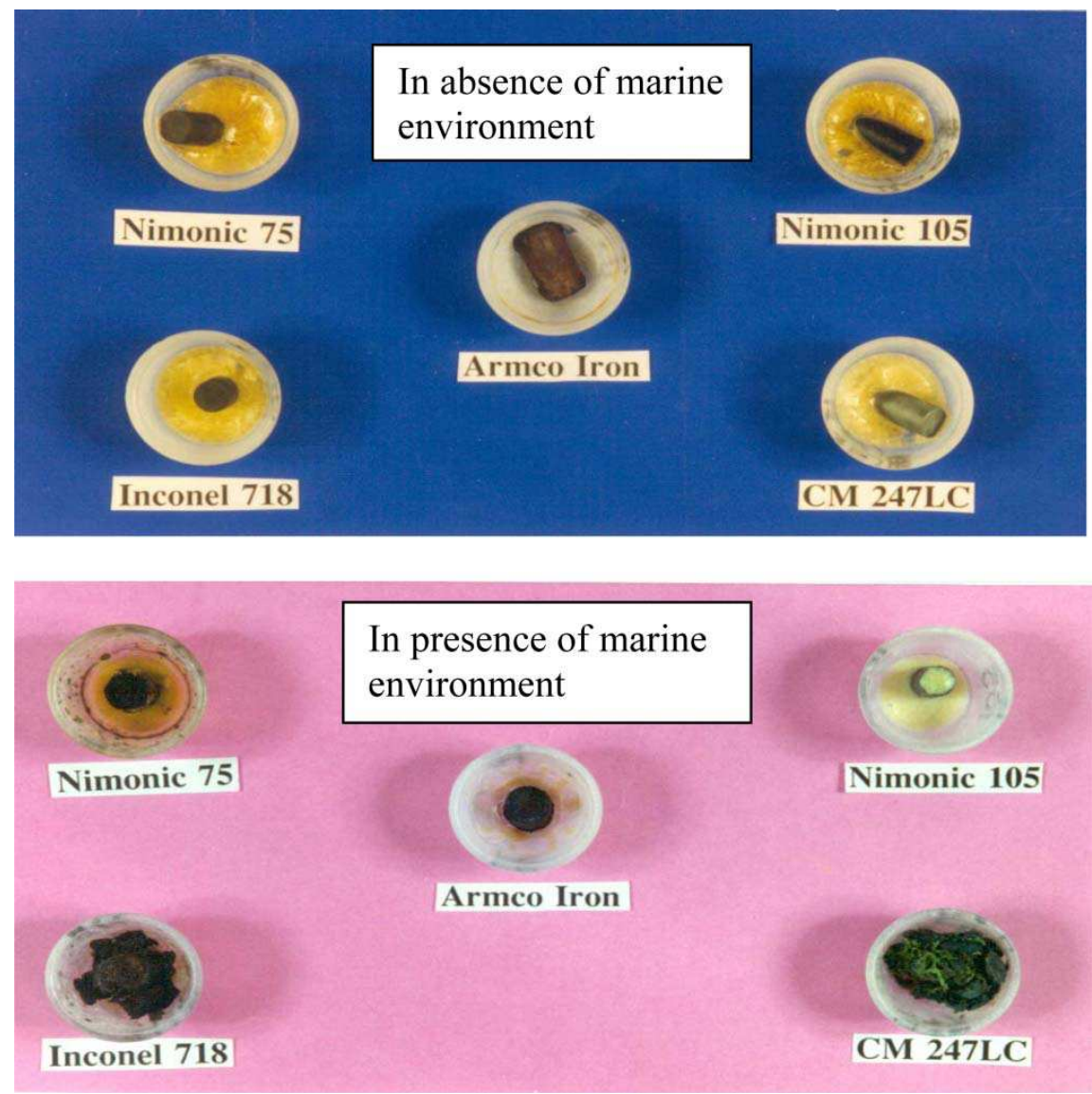

Fig. 9. The effect of marine environment on superalloys under type I conditions 
Figure.9 shows the hot corrosion behavior of few more superalloys like Nimonic-75, Nimonic-105, CM 247 LC etc. corroded in the presence and absence of marine environments under type I conditions. In the absence of marine environment, the corrosion was less for all the superalloys [9]. Appreciable corrosion was observed for all the superalloys in the presence of marine environment. It indicates that marine environment plays a significant role in causing severe corrosion, thereby reducing the superalloy life considerably. Among the superalloys, CM 247 LC was corroded severely indicating that this superalloy is highly susceptible to hot corrosion. In fact many cracks were developed on the scale and subsequently spallation took place. However, there were no cracks and no spallation of oxide scales was reported for other superalloys. In case of CM 247LC alloy, no material was left after exposure of 70 hours to the marine environment and only corrosion products with high volume of corrosion products was observed [9].

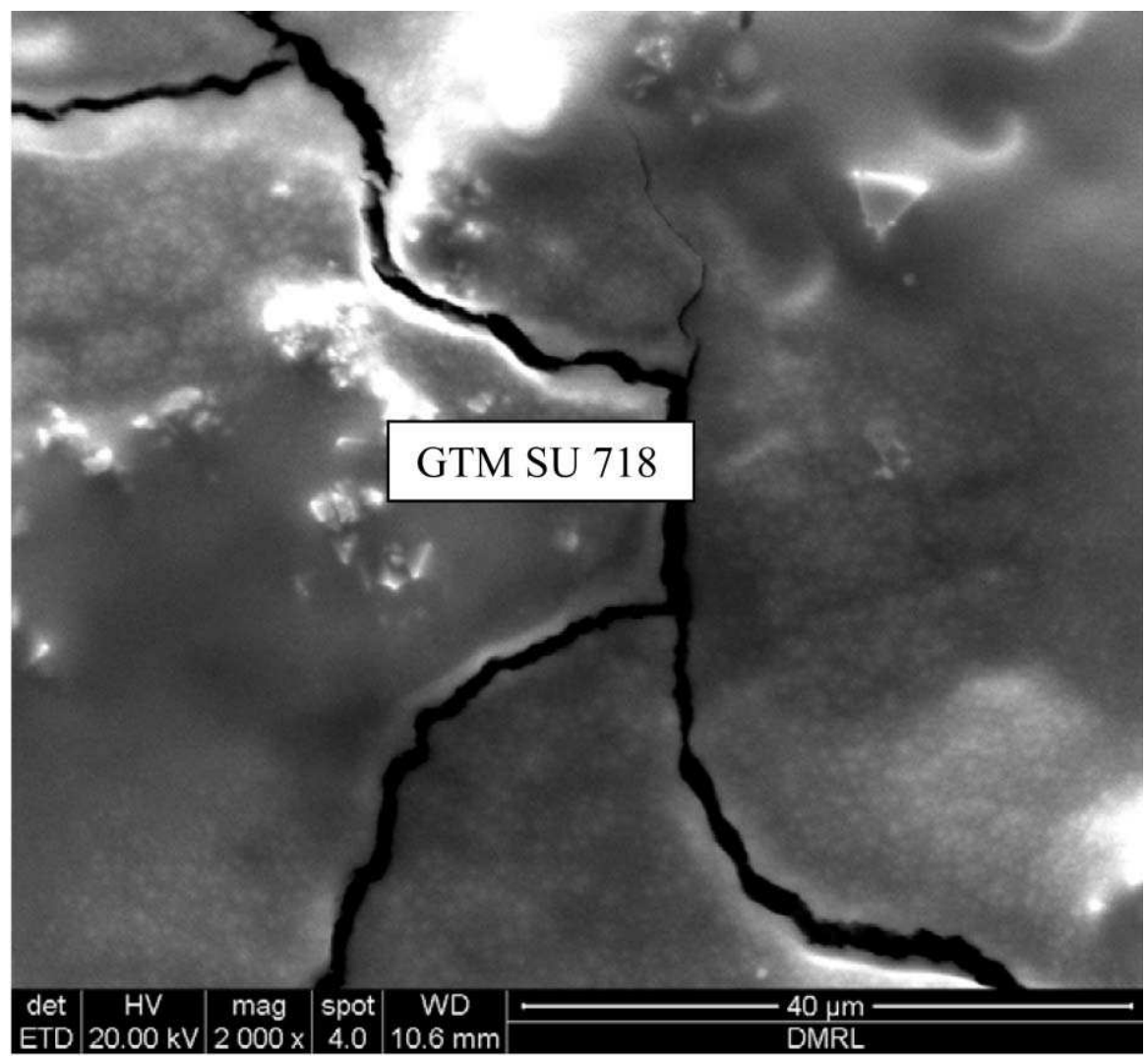

Fig. 10. A typical hot corroded superalloy under type I conditions in marine environment

The surface morphologies of various hot corroded superalloys are revealed that the surface morphology is different for various superalloys under the selected environmental conditions. Electron Dispersive Spectroscopy (EDS) measurements revealed that the corrosion products contain mainly sulphides and oxides of nickel and alloying elements of 
superalloys like Co, Cr, W, Ti, Ta, Re etc. Typical surface morphology of SU 718 (Fig.10) demonstrates the impact of marine environment by forming big cracks. The cross sections of hot corroded superalloys revealed that the corrosion-affected zone is large for all the superalloys (Fig.11). Among them, the affected zone is more for the new superalloy indicating that severe corrosion took place during the hot corrosion process under marine environmental conditions.
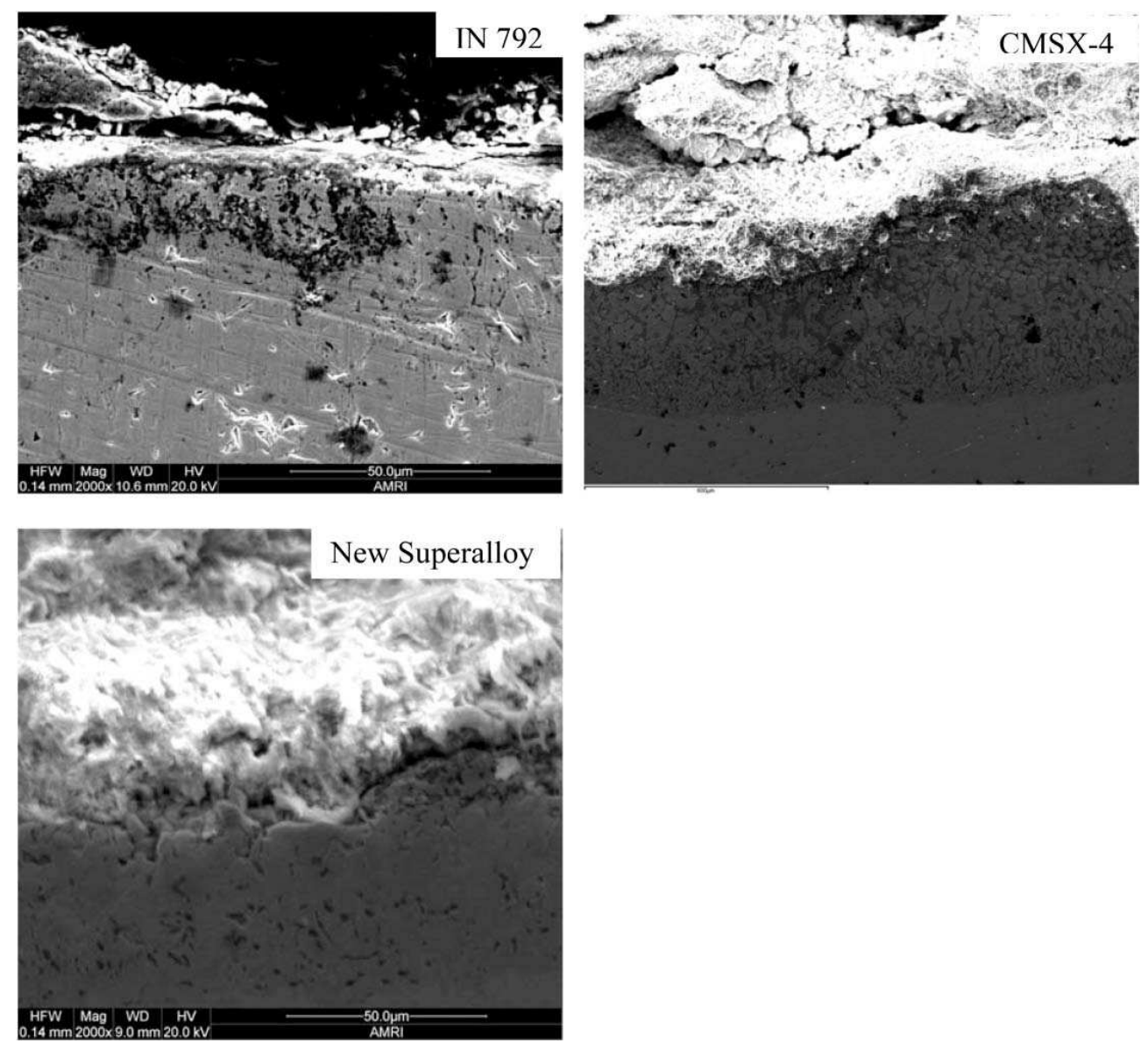

Fig. 11. Cross sections of typical hot corroded superalloys in marine environment

The elemental distributions of hot corroded IN 792 and CMSX-4 superalloys under type I conditions showed that IN 792 superalloy, which contains good amount of chromium (13.5\%) could form continuous chromia scale on its surface. It also promoted alumina as well as titania scales. However, extensive diffusion of sulphur and oxygen into the superalloy was clearly observed. While CMSX-4 that contains about $6.5 \%$ chromium and $3 \%$ rhenium could not form continuous chromia scale. Thin alumina scale was observed on the superalloy surface. Good amount of rhenium was present in the corrosion products. Small 
amounts of sodium and chlorine were also present in the corrosion products but not diffused into the superalloy. However, significant diffusion of sulphur and oxygen into the superalloy was noticed (Fig.12). Extensive diffusion of sulphur was observed in case of hot corroded CM 247 LC alloy (Fig.13). It is to be noted that neither chlorine nor sodium was diffused into the superalloy.

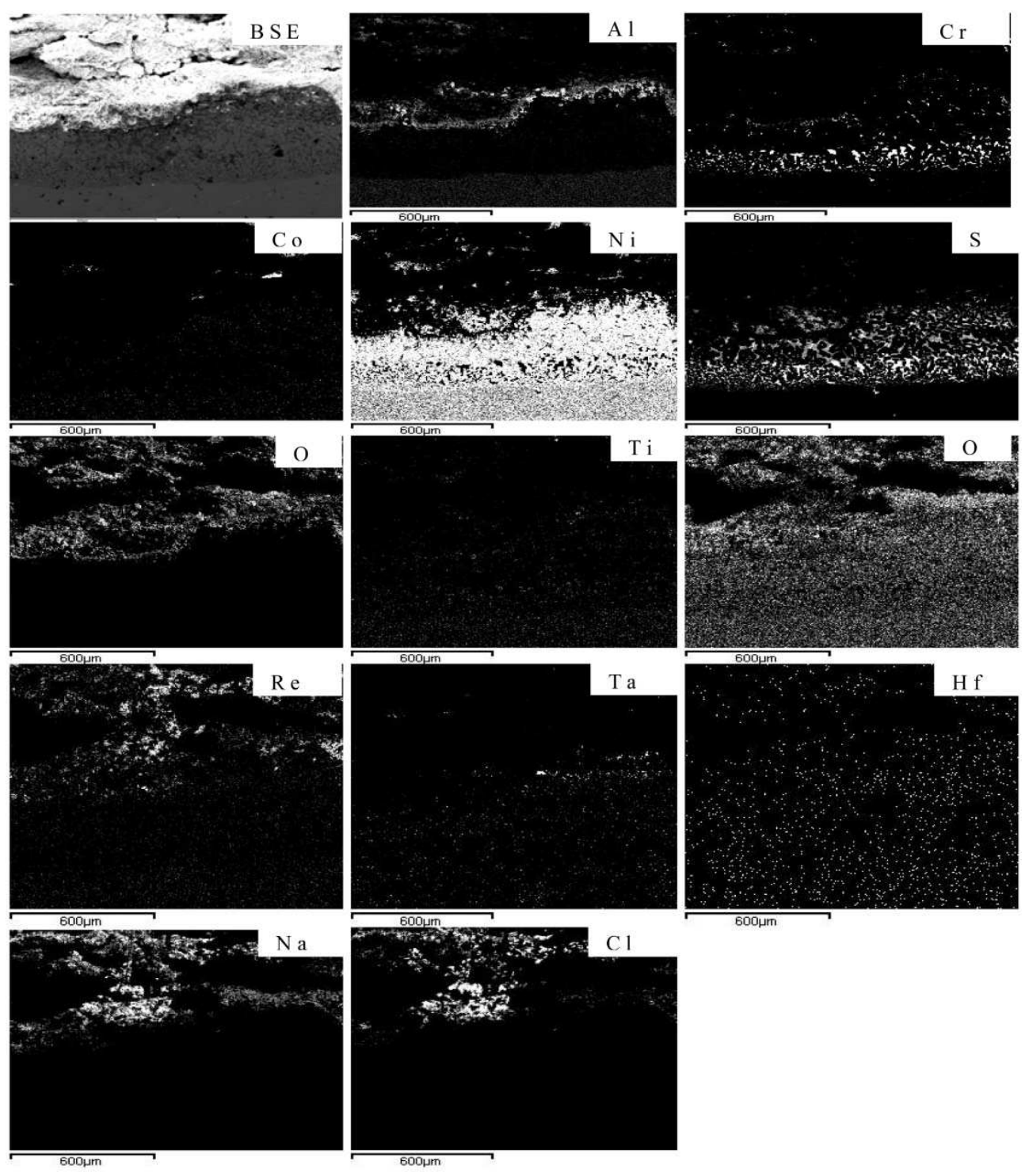

Fig. 12. Elemental distribution of CMSX-4 superalloy after hot corrosion under type I conditions in marine environment 
The elemental distribution of hot corroded new superalloy under type I and type II conditions are presented in figures.14 and 15 respectively. The results showed extensive presence of oxygen, sulphur and sodium in the corrosion products. Considerable diffusion of sulphur into the superalloy was clearly observed under type I conditions while oxygen under type II conditions. Rhenium and tungsten were present in the corrosion products under type I and they were present in the corrosion affected zone of new superalloy under type II. Ta and Hf were seen in the corrosion affected region. It is important to mention here that neither alumina nor chromia formation was observed on the superalloy. It is due to the fact that chromium content in the new superalloy is considerably low. At the same time, other alloying elements could not form any protective oxide scales.

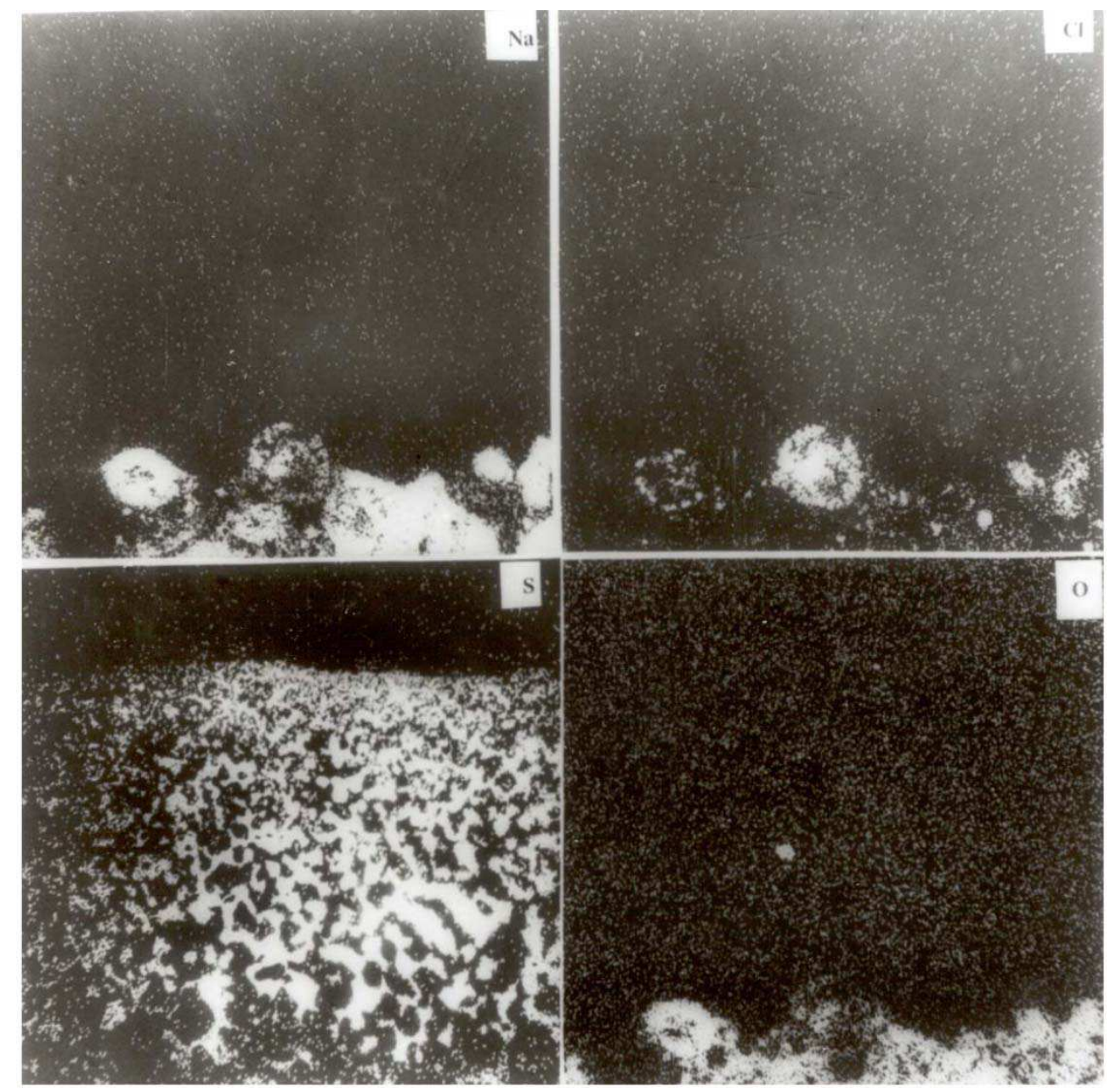

Fig. 13. Elemental distribution of CM 247 LC superalloy after hot corrosion under type I conditions in marine environment 


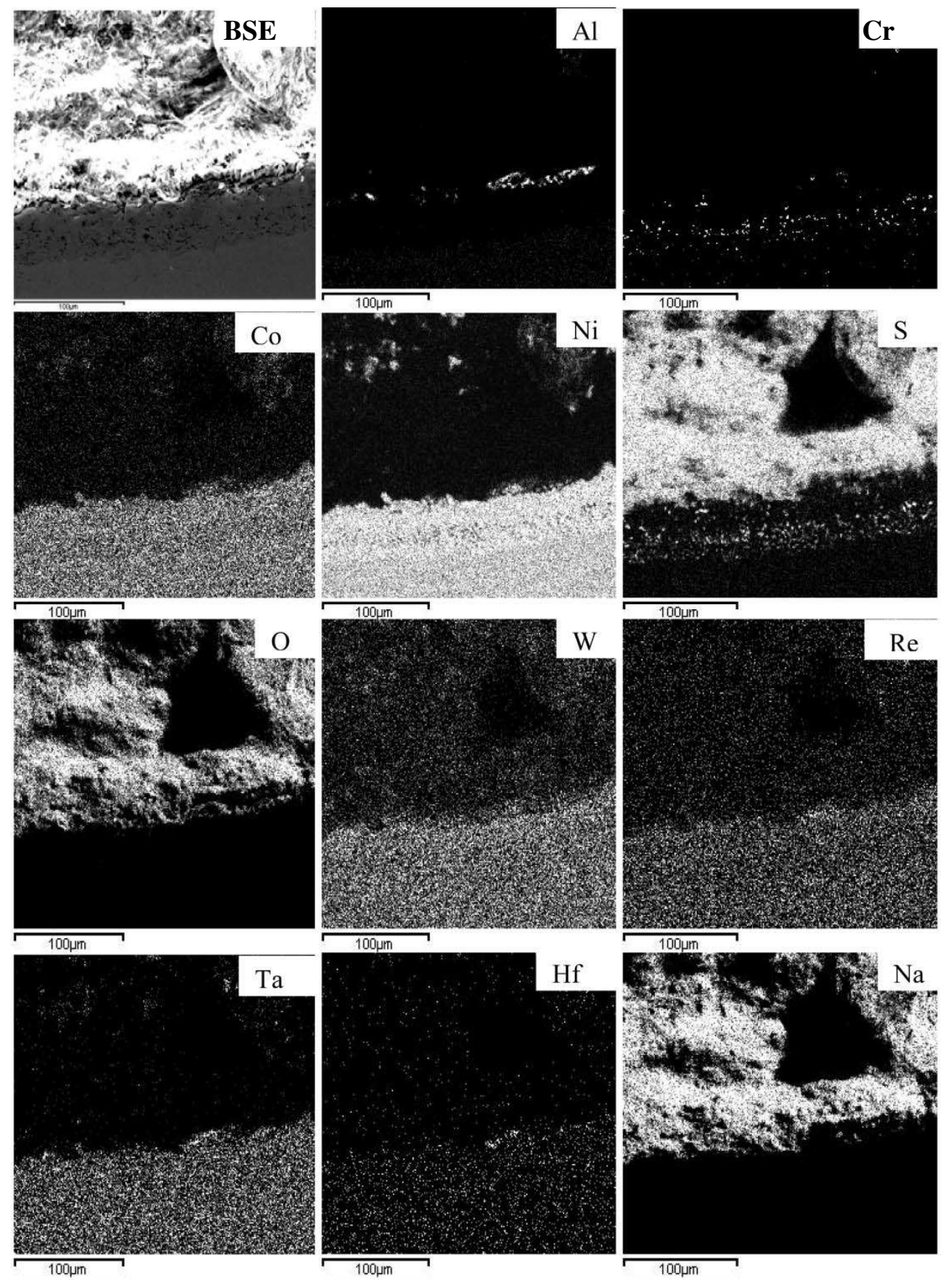

Fig. 14. Elemental distribution of new superalloy after hot corrosion under type I conditions in marine environment 


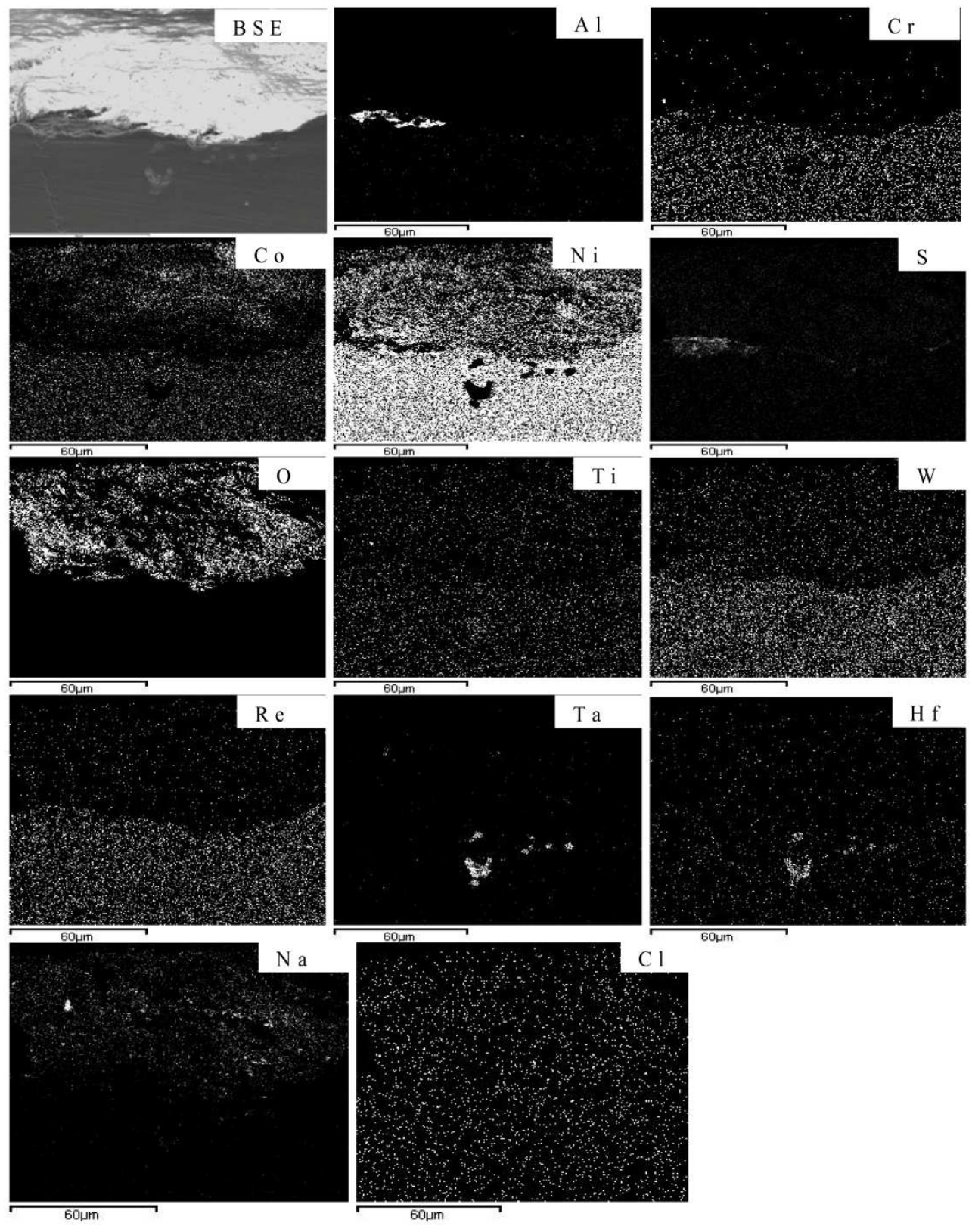

Fig. 15. Elemental distribution of new superalloy after hot corrosion under type II conditions in marine environment 
Sulphur diffusion and formation of metal sulphides preferentially chromium and nickel sulphides was reported to be the influential factor. When sulphide phases are formed in superalloys, Ni- based alloys are inferior to cobalt and iron based alloys, which are especially effective in destroying the corrosion resistance of alloys [12]. In essence, the alloying elements play a significant role and decide the life of superalloys under hot corrosion conditions [12].

\subsection{Effect of alloying elements}

From the metallurgical point of view, it is known that high temperature strength is obtained by maintaining certain phases that are responsible for high temperature strength. Since a main motive for the Metallurgists is to improve the mechanical strength of an alloy at high temperatures, the addition of certain alloying elements is essential with a view to form gamma prime $\left(\gamma^{\prime}\right)$ and solid solution strengthners. Among the alloying elements, the significant reduction of chromium content and the addition of other elements, in particular tungsten, vanadium, molybdenum etc. makes the superalloys more vulnerable to hot corrosion [12]. It is reported that addition of tantalum and titanium produces beneficial effects for hot corrosion [12], while small additions of manganese, silicon, boron and zirconium do not significantly influence the hot corrosion of superalloys. Carbon addition is detrimental to hot corrosion, as the carbide phases provide sites for initiation of hot corrosion [12]. As observed for IN 738 LC with a large amount of chromium and a small amount of titanium, hot corrosion resistance is very good under type I conditions: however the alloy is vulnerable to type II hot corrosion conditions. The addition of molybdenum and large content of iron made the SU 718 less hot corrosion resistant. The addition of large amount of tungsten, tantalum, rhenium and minor other alloying elements and considerably reduced chromium rendered the new superalloy highly susceptible to hot corrosion. It is important to mention that chromium is the most effective alloying element for imporving the hot corrosion resistance of superalloys. In order to obtain good resistance to hot corrosion, a minimum of $15 \mathrm{wt} \%$ chromium is often needed in nickel based superalloys and a minimum of $25 \mathrm{wt} \%$ chromium in cobalt based superalloys [4]. However, it is pertinent to note that other alloying elements play a significant role as evidenced from the reported results. Therefore, it is mandatory to test the alloy under simulated environmental conditions in order to select the more corrosion resistant alloy.

\subsection{Degradation mechanism}

The results clearly revealed that all the studied superalloys are highly vulnerable to hot corrosion. The results further revealed that the new superalloy corrodes much faster when compared to other studied superalloys. It is attributed to the fact that the tungsten which is the alloying element added along with other alloying elements in order to obtain high temperature strength characteristics of the superalloys, forms acidic tungsten oxide $\left(\mathrm{WO}_{3}\right)$ due to which fluxing of protective oxide scales such as alumina and chromia takes place very easily. This type of acidic fluxing is self-sustaining because $\mathrm{WO}_{3}$ forms continuously that cause faster degradation of superalloys under marine environmental conditions at elevated temperatures. The degradation mechanism is explained in two steps as follows: 
a) The tungsten present in the new superalloys reacts with the oxide ions present in the environment and forms tungsten ion

$$
\mathrm{WO}_{3}+\mathrm{O}^{2-}=\mathrm{WO}_{4}{ }^{2-}
$$

b) As a result, the oxide ion activity of the environment decreases to a level where acidic fluxing reaction with the protective alumina and chromia can occur

$$
\begin{aligned}
& \mathrm{Al}_{2} \mathrm{O}_{3}=\mathrm{Al}^{3+}+\mathrm{O}^{2-} \\
& \mathrm{Cr}_{2} \mathrm{O}_{3}=\mathrm{Cr}^{3+}+\mathrm{O}^{2-}
\end{aligned}
$$

A similar reaction mechanism occurs if the superalloys contain other refractory elements like vanadium and molybdenum [9].

\subsubsection{Electrochemical mechanism}

The following section describes an electrochemical phenomenon that explains the new superalloy degradation process in detail under hot corrosion conditions:

Hot corrosion of new superalloy takes place by oxidation of base as well as alloying elements like nickel, cobalt, chromium, aluminium, tantalum, rhenium etc. at the anodic site and forms $\mathrm{Ni}^{2+}, \mathrm{Co}^{3+}, \mathrm{Cr}^{3+}, \mathrm{Al}^{3+}, \mathrm{Re}^{4+}, \mathrm{Ta}^{5+}$ ions etc. while at the cathodic site, $\mathrm{SO}_{4}{ }^{2-}$ reduces to $\mathrm{SO}_{3}^{2-}$ or $\mathrm{S}$ or $\mathrm{S}^{2-}$ and oxygen to $\mathrm{O}^{2-}$. Since the metal ions i.e. $\mathrm{Ni}^{2+}, \mathrm{Co}^{3+}, \mathrm{Cr}^{3+}, \mathrm{Al}^{3+}, \mathrm{Re}^{4+}, \mathrm{Ta}^{5+}$ ions etc. are unstable at the elevated temperature and therefore reacts with the sulphur ions to form metal sulphides. The metal sulphides can easily undergo oxidation at elevated temperatures and form metal oxides by releasing free sulphur (MS $+1 / 2 \mathrm{O}_{2}=\mathrm{MO}+\mathrm{S}$ ). As a result, sulphur concentration increases at the surface of superalloy and enhances sulphur diffusion into it and forms sulphides inside the superalloy. The practical observation of sulphides in hot corroded superalloy specimens clearly indicates that the electrochemical reactions took place during the hot corrosion process. Simultaneously, the metal ions react with oxide ions that are evolved at the cathodic site leading to the formation of metal oxides. The metal oxides dissociate at elevated temperatures to form metal ions and oxide ions. As a result, oxygen concentration increases at the surface and thereby diffuses into the superalloy. Practical observation of oxides in hot corroded superalloys is a clear indication that the electrochemical reactions took place during the hot corrosion process.

Therefore, the hot corrosion of new superalloy is electrochemical in nature and the relevant electrochemical reactions are shown below:

Fig.16 illustrates an electrochemical model showing the new superalloy degradation is electrochemical in nature. Similar mechanism is applicable to other superalloys and their families. The motivation behind suggesting an electrochemical model is to show that the degradation of superalloys in marine environments at elevated temperatures is electrochemical in nature and hence, the electrochemical techniques are quite helpful not only in evaluating them for their hot corrosion resistance but also for understanding their hot corrosion mechanisms. In fact, the electrochemical evaluation of superalloys with and without coatings is more reliable and fast. 


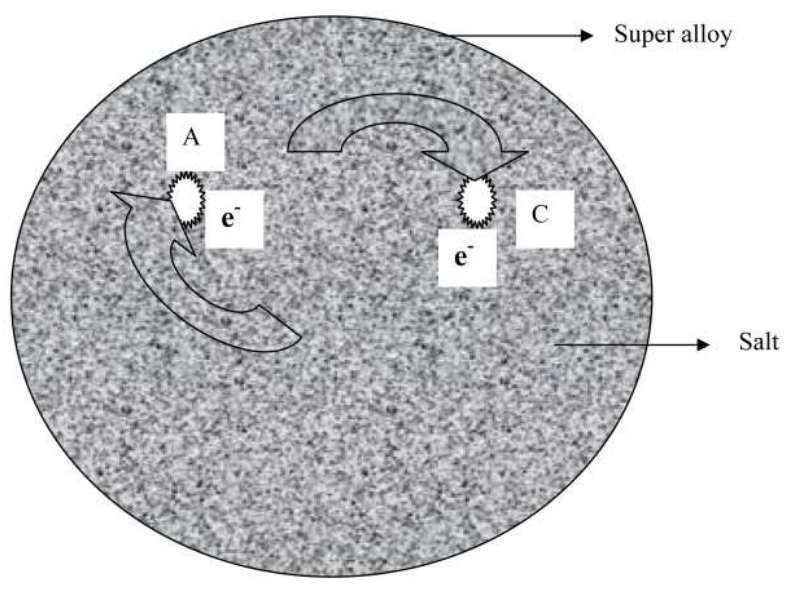

At the anode

$$
\begin{aligned}
& \mathrm{Ni}=\mathrm{Ni}^{2+}+2 \mathrm{e}^{-} \\
& \mathrm{Cr}=\mathrm{Cr}^{3+}+3 \mathrm{e}^{-} \\
& \mathrm{Co}=\mathrm{Co}^{3+}+3 \mathrm{e}^{-} \\
& \mathrm{Al}=\mathrm{Al}^{3+}+3 \mathrm{e}^{-} \\
& \mathrm{Re}=\mathrm{Re}^{4+}+4 \mathrm{e}^{-} \\
& \mathrm{Ta}=\mathrm{Ta}^{5+}+5 \mathrm{e}^{-}
\end{aligned}
$$

etc.
At the cathode

$$
\begin{aligned}
& 1 / 2 \mathrm{O}_{2}+2 \mathrm{e}_{-}=\mathrm{O}^{2-} \\
& \mathrm{SO}_{4}^{2-}+2 \mathrm{e}^{-}=\mathrm{SO}_{3}^{2-}+\mathrm{O}^{2-} \\
& \mathrm{SO}_{4}^{2-}+6 \mathrm{e}^{-}=\mathrm{S}+4 \mathrm{O}^{2-} \\
& \mathrm{SO}_{4}^{2-}+8 \mathrm{e}^{-}=\mathrm{S}^{2-}+4 \mathrm{O}^{2-}
\end{aligned}
$$

Fig. 16. An electrochemical model showing that hot corrosion of new superalloy is an electrochemical phenomenon

\subsection{Development of smart coatings}

From the present results, it is concluded that the new superalloy is highly susceptible to hot corrosion, though it exhibits excellent high temperature strength properties. It is clear that other superalloys are also vulnerable to both types of hot corrosion. It stresses the need to apply high performance protective coatings for their protection against hot corrosion both at low and high temperatures i.e. type II and type I as the marine gas turbine engines encounter both the problems during service. The protective coatings allow the marine gas turbine engines to operate at varied temperatures and enhance their efficiency by eliminating failures during service. Research in this direction has resulted in design and development of smart coatings which provide effective protection to the superalloy components for the designed period against type I, type II hot corrosion and high temperature oxidation that are normally encountered in gas turbine engines which in turn enhances the efficiency of gas turbine engines considerably [14-15]. This is a major developmental work in the area of gas turbine engines used in aero, marine and industrial applications. Unlike the conventional / existing coatings, the smart coatings provide total protection to the superalloy components used in aero, marine and industrial applications by 
forming appropriate protective scales like alumina or chromia depending on the surrounding environmental conditions [14-15].

\section{Titanium alloys}

The titanium alloy components experience hot corrosion problem when they are used for marine gas turbines [16]. It severely limits the high temperature capability of alloys in terms of mechanical properties. It is therefore, desirable to understand the characteristics of titanium alloys under simulated marine gas turbine engine conditions and then apply appropriate coatings, which can prevent hot corrosion and thereby helps in enhancing the life of gas turbine engines significantly.

The hot corrosion characteristics of the titanium alloy, IMI 834 in marine environments at $600^{\circ} \mathrm{C}$ revealed that the rate constant increases by about six times in marine environment and about seven times in vanadium-containing marine environment. It indicates that the rate of reaction is very high in marine environments, still higher in vanadium containing marine environments and low in other environments [16]. The Scanning Electron Micrograph (SEM) of the alloys corroded in marine environment at $600^{\circ} \mathrm{C}$ clearly shows that the oxide scale that formed on the surface of the titanium alloys was cracked due to the presence of $\mathrm{NaCl}$ in the environment (Fig.17). The cracks were not observed for the alloys corroded in other environments. It indicates that the chloride ions present in the marine environment causes the oxide scale to crack and facilitates the corrosive species present in the environment to react with the alloy, which is the reason for observing significant increase in corrosion rate [16]. It is known that chloride ions lead to pitting type of attack, which generally initiates at imperfections in the oxide scale. The micro hardness measurements as a function of depth for the alloys corroded at $600^{\circ} \mathrm{C}$, revealed the presence of about $500 \mu \mathrm{m}$ hardened zone due to dissolution of oxygen, which is sufficient for affecting the mechanical properties of the titanium alloys by forming a highly brittle zone from which crack initiates during service conditions [16]. The depth of oxygen dissolved

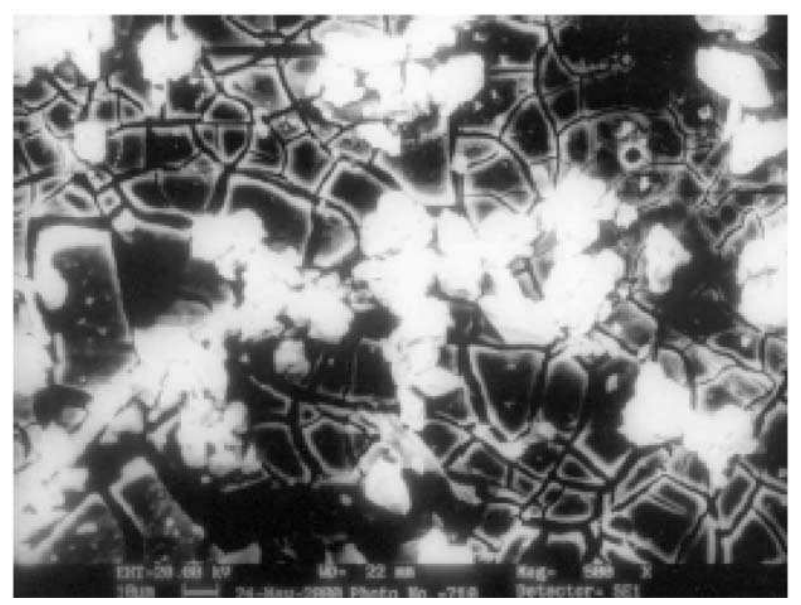

Fig. 17. Effect of marine environment on the stability of titanium alloy IMI 834 
region varies with the temperature at which the titanium alloys were corroded. It is important to mention that the depth of the titanium alloys affected in marine environment is about 100 times more than that of the alloys corroded in other environments at the same temperature [16]. It clearly indicates the greater aggressiveness of marine environments to titanium alloys compared to other environments.

\subsection{Degradation mechanism}

Given below are the proposed mechanistic steps that degrade titanium alloy, IMI 834 under hot corrosion conditions in marine environment:

1. The oxide scale that forms on the surface of IMI 834 is predominantly $\mathrm{TiO}_{2}$ in association with $\mathrm{Al}_{2} \mathrm{O}_{3}$. The $\mathrm{TiO}_{2}$ reacts with chloride ions present in the marine environments at elelvated temperatures to form volatile $\mathrm{TiCl}_{2}$

$$
\mathrm{TiO}_{2}+2 \mathrm{Cl}^{-}=\mathrm{TiCl}_{2}+2 \mathrm{O}^{2}
$$

The $\mathrm{TiCl}_{2}$ dissociates at elevated temperatures to form $\mathrm{Ti}^{2+}$ and $\mathrm{Cl}$ - ions

$$
\mathrm{TiCl}_{2}=\mathrm{Ti}^{2+}+2 \mathrm{Cl}^{-}
$$

The titanium ions then react with oxygen ions present in the environment to form a non-adherent and non-protective $\mathrm{TiO}_{2}$ scale which spalls very easily. Chloride ions penetrate into the alloy to form volatile chlorides. This process continues until titanium in the alloy is consumed. In other words, the reaction is autocatalytic. The oxygen ions that form in reaction (1) diffuse into the alloy and form an oxygen-dissolution region due to high oxygen solubility in titanium alloys.

2. $\mathrm{Al}_{2} \mathrm{O}_{3}$ reacts with $\mathrm{Cl}$ - ions to form aluminum chloride

$$
\mathrm{Al}_{2} \mathrm{O}_{3}+6 \mathrm{Cl}^{-}=2 \mathrm{AlCl}_{3}+3 \mathrm{O}^{2-}
$$

The $\mathrm{AlCl}_{3}$ that formed in the above reaction dissociates to form $\mathrm{Al}^{3+}$ and $\mathrm{Cl}^{-}$ions

$$
\mathrm{AlCl}_{3}=\mathrm{Al}^{3+}+3 \mathrm{Cl}^{-}
$$

$\mathrm{The}^{\mathrm{Al}}{ }^{3+}$ ions react with oxygen ions to form a loose and non-protective alumina scale, which spalls very easily, as in the case of titania

$$
\mathrm{Al}^{3+}+3 \mathrm{O}^{2-}=\mathrm{Al}_{2} \mathrm{O}_{3}
$$

As mentioned above, the chloride ions penetrate into the titanium alloy to form volatile chlorides and the reaction is autocatalytic. The oxygen ions that formed in reaction (3) diffuse into the alloy and react with titanium. The reactions (1) and (3) contribute to the formation of oxygen dissolved region in the titanium alloy subsurface.

As a result of the above reactions, the degradation of titanium alloys takes place at a faster rate [16] and situation can easily make the components fabricated from titanium alloys, susceptible to failure under normal service conditions of gas turbines. Even in actual jet engines, cracking was reported on salted Ti-6Al-4V alloy discs . Logan et al [17] were proposed that oxygen ions from the scale and chloride ions from marine environment, 
diffuse into the titanium alloys, react with alloys constituents to destroy atomic-binding forces and cause cracking. These detrimental observations clearly stress the need to protect titanium alloy components from hot corrosion and thereby enhance their life by avoiding failures during service. These studies also focus on the development of coatings, which can protect titanium alloys both from oxidation as well as hot corrosion, since both the processes are experienced by gas turbine engine components.

\subsection{Smart coatings development}

Different smart coatings based on a variety of elements and their combination were designed and developed on titanium alloy, IMI 834. The extensive investigations revealed that the smart coatings based on aluminium that were developed by innovating a new pack composition showed an excellent resistance both under hot corrosion as well as oxidation conditions [15]. The elemental distribution showed a protective, continuous and adherent alumina scale over the coating. It indicates that an excellent protection was provided by the developed smart coating to the titanium alloys from hot corrosion. Further, the developed coatings can be prepared by a simple technique, easy to coat large components and moreover highly economical. Hence, it is recommended to use the developed smart coatings for the modern marine gas turbine engine titanium alloy components.

\section{Summary}

The chapter presented hot corrosion results of selected nickel based superalloys for marine gas turbine engines both at high and low temperatures that represent type I and type II hot corrosion. The results have been compared with a new alloy under similar conditions in order to understand the characteristics of the selected superalloys. It is observed that the nature and concentration of alloying elements mainly decide the resistance to type I and type II hot corrosion. CM 247LC and the new superalloy are extremely vulnerable to both types of hot corrosion. Relevant reaction mechanisms that are responsible for degradation of various superalloys under marine environmental conditions were discussed. The necessity to apply smart coatings for their protection under high temperature conditions was stressed for the enhanced efficiency as the marine gas turbine engines experience type I and type II hot corrosion during service. Further, the hot corrosion problems experienced by titanium alloy components under marine environmental conditions were explained along with relevant degradation mechanisms and recommended a developed smart coating for their effective protection.

\section{References}

[1] N. Das, US patent 5,925,198, July 1999

[2] M.R. Khajavi and M.H. Shariat, Engineering Failure Analysis, 11 (2004) 589

[3] J.M. Gallardo, J.A.Rodriguez and E.J. Herrera, Wear, 252 (2002) 264

[4] N. Eliaz, G. Shemesh and R.M. Latanision, Engineering Failure Analysis, 9 (2002) 31

[5] M. Konter and M. Thumann, J. Mater. Process Technol., 117 (2001) 386

[6] J. Stringer, Mater.Sci.Technol., 3 (1987) 482

[7] A.S.Radcliff, Mater. Sci. \& Tech., 3 (1987) 554

[8] R.F.Singer, Mater. Sci. \& Tech., 3 (1987) 726 
[9] I.Gurrappa, Oxid. Met., 50 (1999) 353

[10] C.J. Wang and J.H. Lin, Mater.Chem.Phys., 76 (2002) 123

[11] I.Gurrappa and A. Sambasiva Rao, Surf. Coat. Technol., 201 (2006) 3016

[12] I.Gurrappa, Mater.Sci.Technol., 19 (2003) 178

[13] I.Gurrappa, Surf. Coat. Tech., 139 (2001) 272

[14] Gurrappa, J.Coat. Technol. Res., 5 (2008) 385

[15] Gurrappa, Final Report on “Design and Development of Smart Coatings for Aerospace Applications" submitted to European Commission, July 2008

[16] Gurrappa, Oxid. Met., 59 (2003) 321

[17] H.L.Logan et al., Spec. Tech. Publ. No. 397 (ASTM Materials Park, OH, 1966) p. 215 


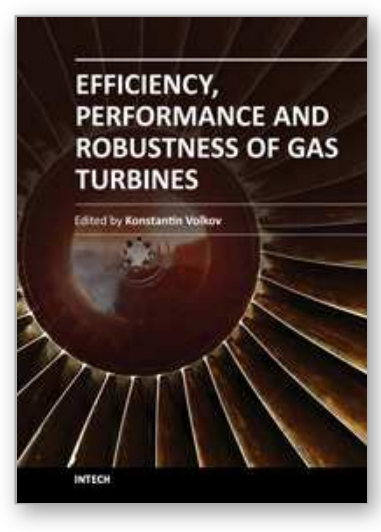

\author{
Efficiency, Performance and Robustness of Gas Turbines \\ Edited by Dr. Volkov Konstantin
}

ISBN 978-953-51-0464-3

Hard cover, 238 pages

Publisher InTech

Published online 04, April, 2012

Published in print edition April, 2012

A wide range of issues related to analysis of gas turbines and their engineering applications are considered in the book. Analytical and experimental methods are employed to identify failures and quantify operating conditions and efficiency of gas turbines. Gas turbine engine defect diagnostic and condition monitoring systems, operating conditions of open gas turbines, reduction of jet mixing noise, recovery of exhaust heat from gas turbines, appropriate materials and coatings, ultra micro gas turbines and applications of gas turbines are discussed. The open exchange of scientific results and ideas will hopefully lead to improved reliability of gas turbines.

\title{
How to reference
}

In order to correctly reference this scholarly work, feel free to copy and paste the following:

I. Gurrappa, I. V. S. Yashwanth and A. K. Gogia (2012). The Selection of Materials for Marine Gas Turbine Engines, Efficiency, Performance and Robustness of Gas Turbines, Dr. Volkov Konstantin (Ed.), ISBN: 978953-51-0464-3, InTech, Available from: http://www.intechopen.com/books/efficiency-performance-androbustness-of-gas-turbines/the-selection-of-materials-for-marine-gas-turbine-engines

\section{INTECH}

open science | open minds

\section{InTech Europe}

University Campus STeP Ri

Slavka Krautzeka 83/A

51000 Rijeka, Croatia

Phone: +385 (51) 770447

Fax: +385 (51) 686166

www.intechopen.com

\section{InTech China}

Unit 405, Office Block, Hotel Equatorial Shanghai

No.65, Yan An Road (West), Shanghai, 200040, China

中国上海市延安西路65号上海国际贵都大饭店办公楼405单元

Phone: +86-21-62489820

Fax: +86-21-62489821 
(C) 2012 The Author(s). Licensee IntechOpen. This is an open access article distributed under the terms of the Creative Commons Attribution 3.0 License, which permits unrestricted use, distribution, and reproduction in any medium, provided the original work is properly cited. 